Article

\title{
Ungendering and Regendering Shelters for Survivors of Human Trafficking
}

\author{
Daphna Hacker ${ }^{1, *}$, Yaara Levine-Fraiman ${ }^{2}$ and Idan Halili ${ }^{3}$ \\ ${ }^{1}$ Buchmann Faculty of Law and NCJW Women and Gender Studies Program, Tel Aviv University, Tel Aviv 6997801, \\ Israel; E-Mail: dafna@post.tau.ac.il \\ ${ }^{2}$ Educational Psychological Services, Tel-Aviv-Yafo Municipality, Tel Aviv 6521128, Israel; \\ E-Mail: yaaralevine@gmail.com \\ ${ }^{3}$ Paul Baerwald School of Social Work and Social Welfare and Faculty of Law, Hebrew University of Jerusalem, \\ 9190501 Jerusalem, Israel; E-Mail: Idan.halili@mail.huji.ac.il \\ * Corresponding author
}

Submitted: 28 August 2014 | In Revised Form: 19 December 2014 | Accepted: 30 December 2014 |

Published: 23 February 2015

\begin{abstract}
This article is based on intensive fieldwork in the two Israeli shelters designated for victims of human trafficking and slavery. The shelters, one for women and one for men, are a refuge for survivors of sex trafficking; labor migrants subjected to severe exploitation by their employers; and asylum seekers who arrived in Israel after experiencing severe physical and emotional abuse at the hands of kidnappers and smugglers en route to Israel. The study included interviews with policy makers and professionals, and with women and men who resided at the shelters, as well as an analysis of the relevant legislation and official reports. The article explores the problematic gendered differentiations between the two shelters. Most significantly, while support for residents of the shelter for women is anchored by emotional and psychological rehabilitation, residents of the shelter for men do not receive any therapeutic support. At the same time, while staff in the shelter for men put significant effort into the reintegration of the men into the labor force, the women's employment prospects receive less attention. Based on these and other findings, the article cautions against gender-biased rehabilitation services for victims of human trafficking and slavery, and calls for a gendersensitive rehabilitation theory and practice.
\end{abstract}

\section{Keywords}

asylum seekers; gender; human trafficking; Israel; labor migrants; rehabilitation; sex trafficking; shelter; slavery

\section{Issue}

This article is part of the special issue "Perspectives on Human Trafficking and Modern Forms of Slavery", edited by Siddharth Kara (Harvard Kennedy School of Government, USA).

(C) 2015 by the authors; licensee Cogitatio (Lisbon, Portugal). This article is licensed under a Creative Commons Attribution 4.0 International License (CC BY).

\section{Introduction}

Since the late 1990s, Israel has been a part of the global phenomenon of human trafficking (Cavaglion, 2010; Ezioni, 2013; Levenkron \& Dahan, 2004), defined by the United Nations as "the recruitment, transportation, transfer, harbouring or receipt of persons, by means of the threat or use of force or other forms of coercion, of abduction, of fraud, of deception, of the abuse of power or of a position of vulnerability or of the giving or receiving of payments or benefits to achieve the consent of a person having control over another person, for the purpose of...the exploitation of the prostitution of others or other forms of sexual exploitation, forced labour or services, slavery or practices similar to slavery, servitude or the removal of organs" (United Nations, 2000, article 3(a)).

The nature of human trafficking in Israel has changed significantly over the last few decades, and remains a dynamic phenomenon. For a period of about ten years and up until 2006, Israel was a prime destina- 
tion for traffickers who smuggled thousands of women from the former USSR into Israel for the purpose of prostitution. While this phenomenon was stopped thanks to active measures taken by the Israeli authorities, there still remain tens, if not hundreds, of survivors of trafficking for the purpose of prostitution living in Israel, no longer trafficked, but still in need of rehabilitation (Haikin \& Safran, 2011). Beyond this, over the last two decades Israel has become a destination country for tens of thousands of migrant workers, especially Asian men working in agriculture and Asian women employed as carers for the elderly (Immigration Authority, 2013). Some of these labor migrants are subjected to extreme exploitation at the hands of their Israeli employers (Nathan, 2009). Additionally, since 2006 about 65,000 people have crossed into Israel from the Sinai Desert in Egypt, seeking asylum as a consequence of war and poverty in their native countries in Africa (Immigration Authority, 2013). Some of these people were tortured by kidnappers, intermediaries and border smugglers in both their home countries and en route to Israel. Torture included forced labor, physical violence and rape, employed, in some cases, for the purpose of extracting ransoms from the victims and their families (Hotline for Migrant Workers, 2011).

In the face of these immigration-related abusive phenomena, Israeli authorities decided to take a firm stance against human trafficking. Their efforts were indeed recognized by the United States' Trafficking in Persons Reports (TIP), which have upgraded Israel from the lowest tier of compliance in 2001 to the highest in its last two reports (Hacker, 2015).

According to international norms, attempts to address human trafficking should incorporate three main spheres of activity: preemptive actions to prevent trafficking; the prosecution of traffickers; and the protection of victims and assistance in their rehabilitation (Gallagher \& Chuang, 2012). This article focuses on the third sphere of activity. One of the objectives of the UN Convention against Transnational Organized Crime (the Palermo Protocol), signed by Israel in 2001 and ratified in 2008, is: "To protect and assist the victims of such trafficking, with full respect for their human rights" (United Nations, 2000, article 2(b)). The protocol also states that "each State Party shall consider implementing measures to provide for the physical, psychological and social recovery of victims of trafficking in persons" (United Nations, 2000, article 6(3)). These measures relate, in particular, to the provision of appropriate housing; counseling and information regarding legal rights; medical, psychological and material assistance; and employment, educational and training opportunities. Signatory states are also required to take into account the age, gender and special needs of trafficking victims; to endeavor to provide for their physical safety while they are within their sovereign territory; to develop legal avenues for the compensation of victims; and to consider adopting means to permit victims of trafficking to remain in their territory, temporarily or permanently, in appropriate cases (United Nations, 2000, part II).

The most significant step taken by the State of Israel to protect and assist in the rehabilitation of victims of trafficking and slavery who are not Israeli citizens is the establishment and operation of two shelters (Israeli Government, 2002, 2007). In 2004, the Israel Ministry of Welfare opened Ma'agan (in Hebrew: Harbor), a shelter for women trafficked for prostitution. The shelter is run by a Non-Governmental Organization (NGO), but is fully funded and supervised by the Ministry. In 2009, the Atlas Center was established, in similar manner, as a shelter for victims of slavery and of human trafficking for the purposes of slavery and forced labor. In practice, the two shelters operate according to the gender of the victims, rather than the types of offences committed against them. They are intended to assist "adult men and women and their children who are the victims of trafficking for prostitution, slavery and forced labor, and who require physical and psychological protection, therapeutic, legal and supportive treatment and accompaniment toward their rehabilitation and their return to an appropriate alternative circle of work, or ahead of their return to their country of origin" (Ministry of Welfare, 2008), (on the definitional uncertainty related to the question who is a victims eligible for rehabilitation, see Hacker \& Cohen, 2012, pp. 58-68). Recently, and after the study reported here was concluded, a third shelter for women was opened, as well as a day center for victims of trafficking who do not live in the shelters (Hacker, 2015).

The establishment of special shelters for the victims of trafficking, with full state funding and supervision, is a pioneering step by the State of Israel, and is rare in the global context. As will be detailed in the next part of the article, in most other countries there are no special shelters for victims of human trafficking; where they do exist, they only serve victims of sextrafficking, and are not necessarily supervised or funded by the state. Notwithstanding, other than public reports produced by the staff of the Israeli shelters (e.g., Davidovich, 2009; Goltsman, 2010), little was known about the assistance and services they provided for their residents, before research conducted by the first author and the late Prof. Orna Cohen, which yielded the findings reported in this article. The objectives of this research project, conducted in 2010 and 2011, were to examine the needs of the populations accommodated by these two shelters; to examine the care provided for them; and to make recommendations for improving policy regarding the rehabilitation of victims of human trafficking, in Israel and in other countries (Hacker \& Cohen, 2012).

One of the most important findings of the study 
was that there was disagreement and confusion as to what was meant by the "rehabilitation" of the victims of trafficking. Unfortunately, the discursive meaning of "rehabilitation" can be influenced by political interests and motivations. For example, the Israeli government supports short-term rehabilitation followed by deportation; NGOs working with victims, and many of the survivors themselves, support long-term rehabilitation and residency permits (Hacker, 2015). No less important is the lack of clarity concerning the meaning of rehabilitation among therapeutic professionals, caused by a lack of experience and know-how regarding the rehabilitation of victims of human trafficking and slavery. Indeed, the professional staff at the shelters interviewed for the study testified that without clear theory and rehabilitation models tailored for victims of trafficking, they were obliged to make attempts, through "small steps as we moved along", to establish intervention tools, based on existing therapeutic models relating to other populations, such as battered women and soldiers suffering from Post-Traumatic Stress Disorder (PTSD).

In this article, we will focus and elaborate on the gendered dimensions of these attempts. We will argue that important practices conducted and services provided in the shelters are problematically gendered, and we will call for a gender-sensitive rather than a gender-biased rehabilitation theory for victims of trafficking.

In the next part of this article, we provide a literature review of the existing rehabilitation services for victims of trafficking around the world, and point to the lack of a rehabilitation theory and models designated for the different kinds of trafficking suffered by women and men. The third part of the article details the study's methodology, and the fourth part explores the findings related to the gendered practices employed in the two Israeli shelters for victims of trafficking. Finally, the concluding discussion connects the findings to theories on gender-sensitive therapy, and proposes basic guidelines for gender-sensitive rehabilitation theory and practice for victims of trafficking.

\section{Literature Review}

As noted in the Introduction, "rehabilitation", is a vague, elusive and dynamic term that can be-and is-defined in different ways by different bodies in keeping with their worldviews and interests. Nevertheless, there is a general consensus among professionals that the process of rehabilitation can mitigate psychological damage and enable the victims to regain their lost rights (Armstrong, 2008). Moreover, trafficking victims who do not receive protection and rehabilitation find it difficult to free themselves from the vicious cycle of suffering and exploitation that they find themselves in due to their life circumstances. Without the opportunities afforded by rehabilitation, they are liable to return to situations which may leave them vulnerable to repeat trafficking (Turner \& Kelly, 2008).

The rehabilitation of victims of trafficking may range from attention to basic needs, such as housing, food, clothing and emergency medical treatment, to comprehensive and long-term assistance that may include psychological support, legal advice, medical treatment, education, vocational training, work placement and reintegration (Brunovskis \& Surtees, 2007). As mentioned in the Introduction, international norms expect countries to work within the more holistic end of this rehabilitation spectrum.

Unlike in Israel, most rehabilitation services around the world designated specifically for victims of trafficking are intended only for women survivors of trafficking for the purpose of sexual exploitation. Rehabilitation services for other populations-such as women, men and children who are victims of trafficking for slavery or for forced labor-are less common (Hacker \& Cohen, 2012), possibly because the current global phenomenon of human trafficking for slavery and forced labor has only been recognized internationally in recent years (Aronowitz, 2009). An additional factor may be the problem of self-identification as a victim: men who have been exploited in a way that correlates with the international definition of trafficking are, nevertheless, less likely to define themselves as victims (Aronowitz, 2009). Moreover, Blanchet (2002), who has examined gender-based aspects of the offense of human trafficking, argues that in conceptual terms, women are more easily identified as victims of trafficking because society is accustomed to perceiving women as victims subject to control by others.

Various types of rehabilitation solutions have been provided to victims of sex trafficking in different countries, including half-way houses, hostels, apartments, closed and open shelters, emergency short-stay shelters and independent homes for victims at the reintegration stage of rehabilitation (Bjerkan, 2005). A high level of variance can be found between different shelters offered to sex trafficking women in terms of security levels, procedures, and the extent to which professional staff intervene in the victims' lives. As a report by the United States Agency for International Development (2007) has noted, each shelter is unique.

Since designated shelters for female and male survivors of human trafficking are not always available, survivors are sometimes referred to shelters and other frameworks intended for other disempowered populations, such as homeless persons, refugees or victims of domestic violence (for a further review of rehabilitation services in different parts of the world, see LevineFraiman in Hacker \& Cohen, 2012, chap. 2; Locke, 2010; US State Department, 2014; United States Agency for International Development Report, 2007). It is important to note, however, that despite the presence of such services, only a small percentage of trafficking victims around the world actually receive assistance (Bales \& Soodalter, 2009). 
Different strategies are used to rehabilitate survivors of human trafficking. As will be detailed below, social workers in the Israeli shelter for female victims of trafficking have adopted Herman's model of trauma and recovery (Herman, 1997), and the concept of "therapeutic community" (De Leon, 2000). Other accepted models, such as Bronfenbrenner's (1979) ecological theory and the posttraumatic growth theory (Bhushan \& Hussain, 2007) have also been used to assist victims of trafficking (Carter, 2012; Twigg, 2012).

Although there is a growing body of literature that focuses on therapy for victims of trafficking (Shigekane, 2007), this article specifically concentrates on the gendered aspects of rehabilitative practices and theory, which have so far been neglected. While it may be that shelters around the world assisting victims of trafficking are implementing gender-sensitive practices, this is neither documented nor conceptualized. The study reported here seeks to begin to address this lacuna.

\section{Method}

Due to the complex and dynamic nature of the research field governing rehabilitation services for victims of trafficking in Israel, the study employed qualitative research methods that allowed for the in-depth, holistic and naturalistic investigation of practices and justifications:

Interviews were conducted with two groups:

(1) Victims: 10 women staying in the shelter at the time of the interviews (four from the former USSR, two from the Philippines, two from Nigeria, and one each from Eritrea and India); five women who had previously stayed at the shelter (three from the former USSR and one each from China and Brazil); 11 men staying in the shelter at the time of the interviews (nine from Thailand and one each from China and Eritrea); and 4 men who had stayed at the shelter previously (two each from Thailand and Nepal).

The ages of the victims ranged from 19 to 46 (mean = 33 for men, 34 for women). Their period of residence in Israel ranged from between several months (for the asylum seekers from Africa) to more than 15 years (for some of the women trafficked for prostitution); their period of residence at the shelter ranged from several weeks (for the agricultural laborers) to more than two years (for a few of the women trafficked for the purposes of prostitution). Most of the interviewees were not fluent in either English or Hebrew, so in those cases the interviews were conducted with the assistance of a translator;

(2) Policy Makers and Professionals: 16 policy makers and professionals in official bodies $(n=12)$ and in Non-Governmental Organizations $(n=4)$, who participated in the development and execution of policy-or who challenged it-relating to the rehabilitation of victims of human trafficking in Israel. (For a full list of names and positions, see, Hacker \& Cohen, 2012, pp. 14-15.)
In addition to the interviews, group discussions were held with the staff of the two shelters (the manager of the shelters, the chairman of the NGO running the shelters, the housemother of the shelters, 3 social workers [ 2 from Ma'agan and 1 from Atlas] and 2 coordinators-one from each shelter). Finally, extensive written material, including laws, Parliament protocols, governmental decisions, ministerial directives, court decisions, and official and NGO reports, were analyzed.

Forty of the forty-six interviews were recorded and transcribed, and were analyzed together with stenographs of the other interactions and with the legal documents and reports (the remaining six were not, due to the interviewees' reluctance to be recorded or due to technical failures).

In order to address the challenges of non-harmful research with victims of trafficking and of obtaining their trust (Bosworth, Hoyle, \& Dempsey, 2011; Cwikel \& Hoban, 2005), the present and previous residents of the shelters were provided with a detailed written explanation of the study, in their native language, before their informed consent was sought, and were not questioned about their past before admission to the shelter, in order to avoid emotional distress. With their permission, information about their trafficking and other abusive ordeals before admission to the shelter was obtained from social workers at the facility. Moreover, the trafficking victims interviewed are all referred to in this article by pseudonyms, in order to protect their privacy.

As noted above, the findings reported here were gathered mainly during the period 2010-2011. Since this research field is highly dynamic, it is possible that some of the aspects reported here have already changed, thus justifying additional and ongoing research.

\section{Findings}

The two studied shelters are situated next door to each other, in a middle-class neighborhood in a city in Israel's central region. They are both part of the same apartment complex, and have been converted to suit the needs of a structure that includes rooms for the residents, public space for assembly, cooking and eating, and offices for the staff. Each shelter has a small yard, and a high fence that both separates it from the other shelter-so female and male residents will not share the same space-and that distinguishes it from the street. Each shelter also has a guard at the entrance, to monitor the comings and goings of the residents and of visitors.

Interviews with the residents confirmed that in both shelters they were provided with a comprehensive spectrum of services, including adequate housing, a sufficient and varied diet, generous medical care and free legal aid covering a wide range of issues relating to 
their presence in Israel. Consequently, in both shelters the residents enjoyed significant physical rehabilitation. Notwithstanding these important and impressive similarities, the study exposed the gendered aspects of the shelters' operation, which, we will argue, are problematic. These aspects-especially those related to emotional and employment rehabilitation-should be addressed locally, but should also serve as a warning sign to authorities and professionals in other countries striving to assist the victims of trafficking.

\subsection{The Shelters' Names}

The gendered aspects of the shelters' operation are symbolically manifested in the names chosen for them by those involved in their establishment. The governmental committee on human trafficking named the shelter for women Ma'agan-Hebrew for a harbor, anchorage. This name signifies the women's need for protected accommodation, a place of refuge from the tempestuous and dangerous world they have emerged from. Like boats steered into a harbor, the name Ma'agan symbolizes the need of the women to be secured to the shelter for protection and repair. The shelter for men, on the other hand, is not even titled a shelter, but rather a center-the Atlas center, a name chosen by the NGO responsible for its operation. According to Greek mythology, Atlas was one of the Titans who revolted against the Gods. His punishment was to carry the world on his shoulders. At the present time, Atlas symbolizes a man tasked with bearing a heavy burden, but who manages to do so thanks to his strength, diligence and resilience. Hence, the name Atlas acknowledges the heavy burden carried by the male residents due to the severe abuse they had suffered, but at the same time portrays them as strong enough to face their condition on their own, and able to endure this for lengthy periods.

Hence, the shelters' names-even if selected unconsciously-fall victim to the known patriarchal trap that portrays women as helpless and passive victims who need to be rescued by others, and men as strong and active agents who can survive on their own (Halley, 2013). The names also echo the gendered patterns of assistance request, documented in the literature, in which women feel more comfortable asking for helpas such asking correlates with the social perceptions of femininity-while men find it harder to ask for emotional assistance, as manifestations of neediness threaten patriarchal perceptions of masculinity (McCarthy \& Holliday, 2004; Yousaf, Popat, \& Hunter, 2014).

\subsection{Freedom of Movement}

When the shelter for women was first established, the police branch responsible for the fight against human trafficking asked for it to be operated as a closed facility. The law-enforcement rationale behind the request was the need to protect the women from their pimps, and to ensure that they remained contactable in order to testify against their traffickers in court. However, the rehabilitation rationale-which objects to the reincarceration of the victims of trafficking, and emphasizes the importance of freedom of movement as an aspect of the victims' recovery of self-esteem (Herman, 1997) prevailed, and both shelters are now defined as open facilities.

However, the two shelters have different rules relating to their residents' freedom of movement. The rules for men are very simple-they are allowed to be out of the shelter during the day but must return by midnight, unless given permission to sleep outside the shelter. With the women, the rules are much more complicated. If they work outside the shelter, they are allowed to leave and return as their employment conditions dictate. But women who are not working are only allowed out of the shelter between 3 p.m. and midnight on weekdays. On Fridays, they may stay out until 5 a.m., and on Saturdays they are allowed out of the shelter from 10 a.m. through midnight. The women are also permitted to sleep away from the shelter twice a month; if they wish to stay away for additional nights, they must receive permission in advance. The guard and the coordinators maintain a list of women with permission to leave the shelter "after hours". The contracts signed by the residents include sanctions for the violation of these restrictions, including the temporary revocation of the right to leave the shelter and the right to pocket money.

Shelter staff justify the restrictions imposed on the unemployed women's freedom of movement as necessary for the establishment of a stable routineincluding group meetings at fixed times-crucial, in the staff's opinion, for the process of rehabilitation. While the men are perceived as already possessing the life-skill qualifications of order, self-organization and self-discipline, the women are perceived as needing to be socialized with these qualifications through an imposed daily schedule within the shelter. As Ada PlielTrossman, who supervised the establishment of the shelters on behalf of the Ministry of Welfare, said, the goal of the contract drafted for the women in Ma'agan, was to establish "boundaries" for the "breached":

"We drafted a contract with 'do' and 'don't'..., boundaries are part of the rehabilitation process. We want to shape normative lives, and to help them place boundaries upon themselves. Indeed, their boundaries were completely breached, internally and externally. This is one of the ways to help them". 
While this might be true for some of the women and for some of the men, such generalizations are extremely problematic as they discriminate against the women when compared to the male residents' greater autonomy; they are also potentially harmful both for those women who would benefit from greater autonomy, and those men who might benefit from a structured daily schedule.

\subsection{Pocket Money}

As part of the package of services provided by the shelters, women receive approximately $\$ 38$ a week in pocket money. Men receive only half of this sum. It is unclear whether the presumption is that women have more expenses, or that men have independent sources of income or savings. In fact, men are less likely than women to be employed while in the shelter, as most were brought to Israel to work in the agriculture sector, and would not be granted work permits for employment in the city or in another occupation.

As it is, for the unemployed residents-and certainly for the men-the pocket money is not sufficient for cell phone calls, local travel, cigarettes, and the purchase of products not provided by the shelter. One unemployed man complained in his interview, like several other male residents: "I am bored. There is not enough pocket money. This closes me in. I have no other money". Without substantial pocket money the male unemployed residents-even more so than the female unemployed residents-are confined to the shelter, and cannot afford to travel anywhere or to subscribe to any kind of leisure activity.

In our opinion, it would have been much more reasonable to provide generous pocket money for those unemployed residents of the shelters, both women and men, and not to give pocket money to those able to work for pay.

\subsection{Emotional Rehabilitation}

The most alarming difference between the shelters lies in the fact that the men do not enjoy the therapeutic services provided for the women, while the women do not enjoy the benefits of the emphasis placed on employment in the men's shelter. This difference strikingly echoes the modern cultural gendered biased division between the emotional female and the breadwinner male (Williams, 1999).

As for emotional therapy, it was evident from the interviews that the concept of rehabilitation relates mainly to women trafficked for the purposes of prostitution. It was evident that the therapeutic professionals were still at an early stage of developing a theory for the other groups of women, and that almost no effort had been put into conceptualizing a rehabilitation theory relevant to the men.
In Ma'agan, each woman is assigned to a social worker, who initiates individual therapeutic sessions to assist her with coping with her trauma. Not all women cooperate, and language and cultural barriers are significant challenges. In particular, the staff do not speak the languages of the newcomers from Africa, and must be assisted by a translator. Moreover, the unfamiliarity of African and Asian women with Western concepts of therapeutic intervention creates a challenge for the staff. This challenge calls for the employment of cultural-sensitive therapeutic tools, but these are yet to be developed in the shelter. Still, individual therapeutic sessions are perceived by the staff as an integral and necessary part of the rehabilitation process of the female residents.

The social workers in the women's shelter seem to have adopted Herman's three stage model of trauma and recovery (Herman, 1997). The first stage centers on bodily safety and emotional stability and control, which are secured through physical rehabilitation and daily routine in the shelter. The second stage includes processing bad memories and experiences in order to relive past traumas - the main source of difficulty for the victims who, in many cases, are afraid or reluctant to tell their stories. The third stage-which not all residents within the shelter reach-aims at relationships rehabilitation and creation. The staff members see their function as facilitating a warm and supportive environment for the women, and as developing the basis for trust and a genuine and positive human relationship without preconditions. The objective is to create the sense of a secure foundation in place of psychological disturbance and confusion-what one woman residing in the shelter referred to as a "mess".

The social workers describe the process of therapeutic intervention as long and uneven. In the early stages, it is often difficult to persuade the women to engage in personal conversations. Subsequent stages seek to connect the women to their own difficulties and fears, to strengthen their emotional state, and to integrate them in activities in the shelter and elsewhere. During the early meetings, the women are remote, frightened and suspicious. Each conversation in this stage lasts about five minutes, but, in some cases, the therapeutic meetings grow longer as time passes and trust is developed. If, indeed, this happens, more significant emotional content begins to emerge. Such progress is uncommon, however. In many cases, the women continue to present a simplistic stance, maintaining that "everything's okay". One of the women trafficked for prostitution, assisted by a social worker at the shelter and a social worker at a health clinic in which she was treated, described how hard it was for her to open up during therapeutic sessions, and how rewarding it was:

"When I first began the sessions, I felt bad about 
letting it all out. It hurt, I cried a lot...It took me six months. But she [the social worker at the clinic] was so good; she understood that it was hard for me, so she moved at a very slow pace. Now, after therapy with both of them [the social workers at the clinic and at the shelter], things are much calmer. And I can even think more easily. It's better, and I think I am also a better mother to my child".

Another therapeutic concept employed by the staff at Ma'agan is the "therapeutic community". This concept aims to promote the future integration of the individual in society. Accordingly, the function of such a community-the shelter, for our purposes-is to provide the individual with the habits that will facilitate her or his integration into normative life. The emphasis is on norms and values like trust, concern for others, responsibility and honesty. These are basic norms and values that relate to any social framework in which the victims may find themselves. The community inculcates these values through daily activities emphasizing social learning. The difference between the community and the "outside" world is that the community promotes learning through a process of trial and error, offering a safe and accepting environment within which the individual can fail without repercussions. Thus the therapeutic method, in essence, is the community (De Leon, 2000).

In additional to daily routine, behavior rules and cooking and cleaning duty rosters, the concept of therapeutic community is manifested through group meetings, held in the women's shelter three times a week, on a fixed day and time. All the women in the shelter at the time are expected to attend the sessions, led alternately by the shelter's coordinator, the house mother or a social work student. The therapeutic importance of this framework lies in the ability to commit to a set schedule, to listen, and to give and receive feedback, though the content itself does not relate directly to emotional aspects. These sessions serve two practical purposes: they give staff the opportunity to update all the women about activities in the shelter, and they also enable the women to raise issues of concern relating to the daily routine in the shelter. The staff feel that this reduces tensions, releases pressure, and enables the women to talk respectfully to, and about, each other.

In addition to the general meeting, the group of women from Africa also meets separately, with the help of an interpreter. These meetings do not take place on a regular basis. According to the shelter's staff, this is so because these women find it difficult to get up in the morning (since they suffer from sleeping problems at night), and to follow a punctual timetable. They have to be brought individually and accompanied to the meeting. These sessions provide an opportunity for the group coordinator to explain, repeatedly, basic technical matters and for the women to express their concerns.

Finally, in 2009 a voluntary empowerment group operated in the shelter, moderated by a Russian speaking woman who was also a recovering drug addict. The group operated according to the Twelve Steps method, and focused on diverse issues, such as insecurity, low self-esteem, intimacy, self-realization, sex work in the past, and changing behavioral patterns. According to the counselor, several difficulties emerged over the course of the work. These include the difficulty in encouraging ongoing and consistent participation; the difficulty in focusing on painful issues; and the reluctance of the women to "connect to their inner selves" (Davidovich, 2009). During the research period, efforts were made to find a counselor to run a new such group.

In the case of the men however, the professional staff at the shelter hold individual and group sessions only during the first few days of intake, with the help of interpreters. These sessions are mainly informational and organizational in content, and aim to help the new residents understand why they are at the shelter and what they can expect during their time there. Virtually no individual or group therapeutic conversations take place within the men's shelter. Indeed, though each shelter is designated for the same number of residents (35), the governmental tender for their operation requires that the NGO running them appoint two full-time social workers for Ma'agan, but only one full-time social worker for Atlas (Ministry of Welfare, 2008). Moreover, during the research period, the women's shelter staff indeed included two fulltime female social workers, but there was no male social worker at the men's shelter, and its staff included only a solitary, part-time female social worker. No rationale was presented during the interviews or within the official documents as to why there were no therapeutic interventions in the men's shelter. After the fieldwork was concluded, a male social worker and a male instructor who spoke Amharic were added to the team at Atlas; this may have resulted in more attention being given to the men's therapeutic needs.

A case that demonstrates the problematic nature of the presumption that men do not require therapeutic intervention is that of Chen Gua Jie. Chen paid $\$ 25,000$ to what he believed was an agency that will help him get from China to Israel, to work in construction. However, he was cheated by human traffickers and was taken hostage in Egypt. He was kept prisoner for several months in the desert, in conditions of forced labor and physical abuse. During this period, the smugglers who held him hostage attempted, unsuccessfully, to smuggle him across the border several times. Chen escaped from the smugglers' camp and walked for 40 hours to reach the Israeli border. He was caught immediately after crossing the border and put 
in a detention center. There, he tried to kill himself by swallowing a pair of scissors, out of desperation concerning his debts, his fear of imminent deportation to China and fears for the wellbeing of his family members. After the suicide attempt, he was moved to Atlas, the men's shelter, and had resided there for eight months at the time of interview. He did not receive any kind of psychological treatment, although his circumstances clearly demonstrate his need, and even though during the research interview he clearly stated his wish for therapeutic assistance.

Likewise, it was evident from the study that the men could have benefited from group meetings. During the research period, a violent fight broke out, between several residents from Thailand and one of the residents from Eritrea, over control of the remote control for the single television in the shelter. Not only were these men only interested in the TV channels transmitted in their different native languages, the lack of a common language makes it hard to resolve disputes verbally. Without routinized, mediated and translated group meetings to discuss such issues as how to divide TV time fairly among residents interested in watching different channels, it is impossible to address the male residents' practical needs emerging from the communal nature of the shelter. Moreover, an opportunity to create a "therapeutic community", which will address their emotional needs-caused by the abuse they suffered from before entering the shelter-is missed.

\subsection{Employment Rehabilitation}

While both shelters are aimed-among other targets - at assisting the residents in employment rehabilitation, the research findings point to a stronger emphasis on employment within the men's shelter. The staff at Atlas strive to find decent employers for the residents; support the men and help them maintain their jobs; and provide assistance if difficulties arise with the new employer, either because of language or cultural barriers, or due to problematic attitudes on the part of the employer. The staff perceive these functions as central to their role. Meir Hovav, chairman of the NGO running the shelters, observed during one of the group meetings we conducted with the staff of the shelters, during a discussion on the lack of emotional rehabilitation at Atlas: "At the moment we focus on alternative employment, finding them employment. Everything else is marginal".

Indeed, the staff's position is that once a work permit is issued and a decent employer located, the male residents should be integrated into the labor force. There was no indication that consideration had been given to the possibility that the victim might be in such a severe emotional state that employment could be emotionally harmful, and that rest and reha- bilitation ought to be the immediate priority. Since most of the men at the shelter at the time of the study were labor migrants who came to Israel legally to work in agriculture, they left the shelter the minute a decent employer within the agriculture sector was located by the shelter's staff. Hence, only few of the men stayed at the shelter for more than a few weeks, regardless of the degree of abuse they suffered from previous employers and the degree of emotional distress they suffered as a result. Once in a new place of employment, they become obliged to work long and tiring hours, without emotional support.

It is important to note that all the men interviewed voiced a strong desire to go back to work, and were frustrated by the unemployment waiting period at the shelter. For example, one of the residents describes his feelings after being brought to the shelter by the police, after raiding his abusive employer:

A: I knew nothing. Later we asked the staff here, and they explained to us that we need to wait for police approval, and then they will help us with the visa and will send us to work outside. But it took a month or so before we received all the authorizations.

\section{Q: And you consider this a long time?}

A: Yes, a long time. I was scared.... We spent a lot of time here [at the shelter], too much time, and all I had in my head was that I had no money to send home and no work, and I did not know what will happen, and when. Yes, it was a long time.

Many of the male residents had taken loans to come to Israel, and were desperate for sources of income to repay the loans, as well as to be able to send money home to their families. Notwithstanding, some may have been satisfied with jobs outside the agriculture sector, which would have allowed them to earn money while staying at the shelter and benefitting from rehabilitation services. Unfortunately, as mentioned earlier, the Israeli Minister of Interior, responsible for the issuance of residency and work permits, insists upon these labor immigrants remaining restricted to the agriculture sector.

For the asylum seekers in the shelters, securing a work permit and finding suitable employment is more difficult, as they were not officially allowed to enter Israel and come to the shelter without either residency or work permits. Thus, they tend to remain at the shelter for longer periods, and without income. Still, the freedom of movement they enjoy at the shelter allows them to take the risk of working illegally to earn money. This, of course, puts them at risk of deportation, and highlights the need for work permits-at least temporary ones-for all the residents of the shelters. Those who refuse to take the risk of working illegally 
are in the same dire state as the unemployed labor migrants, as they also are desperate to earn money in order to pay their loans and to send money home.

For residents whose welfare might be at risk if reintegrated into the labor force, or who cannot work due to the lack of a valid work permit or other reasons, the clear need for an ongoing income source could be addressed by a temporary unemployment allowance, which would allow for a necessary period of physical and emotional recovery before reintegration into the labor force, and for the economic wellbeing so crucial in supporting emotional wellbeing.

This is also true for the women, as employment rehabilitation for many of them is even more complex than it is for the men. Many of the female residents have no occupation or profession, and may even lack basic employment skills. There is general agreement among policy makers and shelter staff that a key objective of rehabilitation is to provide the women with the work habits and vocation that will help them integrate into normative life after leaving the shelter, and particularly after their return to their countries of origin. Indeed, a vocation does not merely provide a livelihood, but also provides a sense of self-value, confidence and belonging (Rossoa, Dekas, \& Wrzesniewski, 2010).

Since the opening of the shelter, reflection and resources have been invested in attempts to provide the women with courses meeting the needs of their countries of origin and commensurate with their wishes and abilities. Rinat Davidovich, the first manager of Ma'agan, describes these efforts:

"We consulted with organizations in the countries of origin: what did they think would be effective training for the women here, what could they learn here and do there? Because a woman can fantasize about something unrealistic, you see? I could teach the Thai women computers, but so what? What will they be able to do with these skills there? So, we wanted to do something effective, something worthwhile for them. So we traveled to meet women who had stayed with us and subsequently returned to their home countries, and learned from them what would help with reintegration".

These assessments resulted in courses in secretarial work, nail technology, cosmetics, cooking, sewing and hairdressing. Israeli Parliament Member Zehava Galon, head of the Parliamentary Committee for the Investigation of Trafficking in Women in 2000-2005, and the Parliamentary Committee for the Struggle against Trafficking in Women, which followed, in 2005-2008, recalled in her interview how critical she was of this choice of courses:

"I visited the shelter and I was told that they were going to train the women in cosmetics and sewing, or something like that. And I said, 'What is this nonsense? They worked in prostitution, so they need to learn cosmetics? And, who is sewing these days?"”

Galon persuaded a leading bank to donate several computers to the shelters, and convinced the Ministry of Welfare to offer to the women a course in computer skills.

Vika Goltsman, director of the shelters at the time of fieldwork, emphasized the complex nature of the debate as to whether employment should come before training or vice versa, as well as the question as to whether the training should be adapted to employment opportunities in the women's countries of origin, or in Israel. These issues have been discussed since the establishment of Ma'agan without reaching any firm conclusions. The staff in the shelter focus its efforts on locating employers willing to train inexperienced women; locating and funding relevant vocational courses; and adapting vocational training to reflect the participant's level of spoken and written Hebrew.

Notwithstanding these efforts, and due to the heterogeneous nature of the population in the shelter in recent years, it is more difficult today than in the past to bring together a group of women who share a common language and are interested in studying a specific vocation. There is also a shortfall in funding for advanced diploma studies in fields such as baking or manicuring, for women interested in these fields. Most alarming is the finding that during the research's fieldwork period (a year and a half), no vocational courses were provided for the women in the shelter; and none of the women were sent to vocational courses outside the shelter, with the solitary exception of a basket-weaving course for residents from Africa, offered by an NGO assisting African asylum seekers. Moreover, since most of the women entered Israel without the requisite entry permits, the Ministry of Interior is hesitant and sometimes reluctant in issuing them work permits. Thus, there are several residents forced to stay at the shelter for months and even years, without the ability to work and earn money, at least legally. Even so, this acute situation did not lead to a decision to issue temporary work permits to all residents, or to give unemployment allowances for those not permitted to work.

Like the men, the women interviewed were preoccupied with their need for constant and sufficient income. In particular, they referred to the economic needs of family members in their home countries, and the financial demands they want-and are expectedto answer, such as school tuition or a sick mother's medical bills. For example, one of the women, who found work at a Sushi restaurant, said:

"I'm a single mom. I make sushi because my Mom is 
very sick and needs an operation. She is already blind....That's why I send all my salary to my mother and my daughter".

In addition, it was clear from the interviews that an independent economic existence is crucial to safeguarding the women at the shelter from abusive relationships with Israeli spouses and from repeat trafficking, as will be discussed in Section 4.8 bellow.

\subsection{Leisure Activities}

The residents of Ma'agan and Atlas Shelters enjoy enrichment activities designed to help them adapt to life in the shelters, to fill their leisure time with meaningful content and to provide enjoyable experiences as part of the process of healing and rehabilitation. These activities include courses in Hebrew and English, cable television and the occasional organized tour outside the shelter. Interestingly, only the women's shelter is equipped with a library, and only the men's shelter has a courtyard big enough for ball games, and is equipped with a tennis table. Indeed, while the men organize group sporting activities, the women do not. This is but one example of the more individualistic nature of the women's experience in the shelter. Contrary to stereotypical perceptions of natural female bonding, the women do not participate in voluntary group activities, and usually bond-if at all-only with one other resident, usually of the same ethnic origin. Enmity between the different ethnic groups, which also correlates with the different kinds of abuses suffered by the residents, is evident in both shelters, creating an additional obstacle to rehabilitative and restorative residency in the shelters.

Notwithstanding the above mentioned and other leisure activities, the dominant atmosphere in both shelters is one of boredom and stagnation. The abundant free time, coupled with the absence of additional suitable activities - such as herb gardening, for example, or a television channel in Thai and latest newspapers from their countries of origin-all contribute to a negative impact on the residents of the shelters, particularly with those residents who are not permitted to work due to the lack of legal status. It is evident that the residents are not consulted about the activities that suit their needs and interests, including those due to their gendered preferences.

\subsection{Motherhood, Fatherhood and Children}

An obvious gendered aspect of the shelters is that Ma'agan is prepared to host residents' children, while no such provisions exist at Atlas. Indeed, between four and ten children have stayed in the women's shelter each year since its establishment. These children were born to women trafficked for prostitution, from rela- tionships they had had with Israeli men. No child has ever stayed in Atlas. A common theme to both shelters is that the labor migrants and asylum seekers did not bear children in Israel. Notwithstanding, and as noted above, some of the residents belonging to the latter two groups do have children in their countries of origin. While some emphasis is put on the difficulties of long-distance motherhood and on maternal skills in the women's shelter, no reference to paternal responsibilities and sentiments was observed at the men's shelter.

\subsection{Leaving the Shelter}

Finally, the gendered differences between the shelters are also evident in relation to staff practice regarding residents who leave the shelter.

As mentioned above, at the time of the research, most of the residents in Atlas were labor migrants from Asia who came to Israel legally, to work in agriculture. In relation to this group, the staff members started, during the research period, to initiate visits to their employer's site. In the course of their visits, the staff members meet with past residents, ascertain that they are not being exploited, and provide a sympathetic ear if problems arise with the new employer. For example, the social worker at Atlas mentioned in her interview that one of the residents interviewed for the study was recently placed with a new employer, and that she had traveled to the south of the country to visit him and other former residents sent to the same employer. She reported that "everything is fine. They are very pleased".

Moreover, many of the men who leave the shelter continue to perceive it as a source of support and as a base to which they can return. They are grateful for this, maintain contact with the staff, and visit the shelter from time to time when they are in central Israel (in Israel, agricultural work is mainly in the north or south of the country). The staff at Atlas even allow former residents to sleep in the shelter and use its facilities occasionally, even after they have officially left to work with new employers.

The picture is very different in relation to past residents of Ma'agan. Women tend to leave the shelter for one of three main reasons: return to their country of origin; a relationship with an Israeli partner; or departure "without authorization", when women simply take their belongings and leave without giving notice. The research findings point to the absence of formal and consistent procedures for maintaining contact between the shelter staff and women who have left Ma'agan but who remain in Israel. Likewise, shelter staff do not always maintain direct contact with residents who return to their countries of origin. In many cases, if the woman who leaves the shelter does not initiate contact by means of telephone calls or letters, she becomes "lost" to the staff. However, in 2011 the 
shelter staff sent a New Year's gift to the women with whom they had remained in contact.

These findings are troubling since victims of trafficking are invariably at risk of repeat abuse, whether in their country of origin or country of destination (Adams, 2011). In the first case, the lack of contact prevents staff from making sure that past residents have returned safely to their country of origin, and to provide assistance by contacting the relevant authorities and local NGOs if they suspect that she may be in danger. In the latter case, the fact that the women who remain in Israel do not perceive the shelter as a haven in times of need-unlike their male counterparts-can put them at risk if and when such a need occurs.

\section{Concluding Discussion}

The research findings show that while Israel is a rare example of a country that offers state supervised and funded shelters for survivors of trafficking and slavery, these shelters are problematically gendered. The women's shelter is centered on the notion that its residents are in need of emotional and basic life-skills rescue, less so of economic independence; the men, on the other hand, are perceived as fit for re-fulfilling their roles as breadwinners, regardless of the severity of the abuse they may have suffered from and its emotional consequences. As detailed above, this dramatic difference is compounded by other unjustified gendered differences related to freedom of movement, pocket money, leisure activities, parenthood, and follow-up upon departure of the shelter.

The starting point for the discussion of the findings presented above is the distinction between gender-biased therapy and gender-sensitive therapy. The American Psychological Association identified four general areas of gender bias in therapy: (1) Fostering traditional sex roles; (2) Bias in expectations and devaluation of women; (3) Sexist use of psychoanalytic concepts; (4) Responding to women as sex objects, including the seduction of female clients (APA, 1975, in Good, Gilbert, \& Scher, 1990). The research findings indicate the existence of the first and second biases within the studied shelters. These biases include the tendency to reinforce the women's victimization rather empowering them through financial independence; providing limited employment training opportunities, which reinforces gender stereotypes; limiting the freedom of movement of the female residents of the shelter; and emphasizing the male role as the breadwinner, at the expense of their emotional rehabilitation. We claim that these findings should serve as a warning for policy makers and professionals seeking to assist victims of trafficking and slavery, and that the frameworks established to provide such assistance should be carefully tailored as to become gen- der-sensitive rather than gender-biased.

Gender-sensitive therapy is referred here as a synthesis of feminist therapy and gender awareness (Good et al., 1990). Although feminist therapy seems to have been designed for women, there is a growing body of literature to support the view that male clients can equally benefit from it. Feminism is constituted from a wide range of points of view, but there are several shared themes that underline feminism and the principles of feminist therapy. Feminist theorists and practitioners developed principles for gender-sensitive therapy. For example, Good et al. (1990) suggest employing the following five principles of gender aware therapy: (a) Regard conceptions of gender as integral aspects of counseling and mental health; (b) Consider problems within their societal context; (c) Actively seek to change gender injustices experienced by women and men; (d) Emphasize the development of collaborative therapeutic relationships - in the therapeutic process, the therapist helps the clients to discover solutions for themselves; and (e) Respect the clients' freedom to choose what is right for them, despite gender conceptions, political correctness or dogma. Another example of the principles of gender-aware therapy is offered by Dominelli and Campling (2002), who leans on several feminist theoreticians including Kate Millet, bell hooks, Patricia Hill Collins and Nancy Adamson, to develop a gender sensitive therapeutic view, based on: (a) The integration of personal and political elements of life; (b) Respect for women's diversity; (c) Seeking egalitarian forms of social relationships; (d) Acknowledging that the patriarchal social order serves both men and women badly, and therefore should be transformed. All these feminist principles can be used as an infrastructure for practitioners, including in shelters for victims of trafficking.

A counselor employing a gender-sensitive approach should also be aware of his/her own biases, concepts, experiences and beliefs towards femininity and masculinity. The counselor must be aware of the influence of the gender context on patient behavior, including the gender of the therapist her/himself (Deering \& Gannon, 2005; Good, Thomson, \& Brathwaite, 2005). Moreover, gender-sensitive rehabilitation interventions must take into account knowledge about gender, including gender constructs and socialization, and in particular must be aware of gender power relations (Chantler, 2005; Mejía, 2005). Power relations in the context of rehabilitation services for victims of trafficking present multiple facets: gender, ethnicity, nationality and social class-based power imbalances are all present. Even the fact that the rehabilitation center itself may be a governmental arm that the residents are dependent on-and may be suspicious of, due to their immigration status or past traumatic experiences with governmental bodies-is part of the power imbalance that the counse- 
lor at the shelter should be aware of and address.

As noted above, gender sensitive therapy-which might take place in shelters and in other rehabilitation settings for trafficking victims-is especially attuned to female stereotypes. Women are culturally considered passive, needy for protection, economically dependent on men, and emotionally vulnerable (Gilbert \& Scher, 2009). As the findings demonstrate, while the residents of Ma'agan receive generous emotional rehabilitation, vocational rehabilitation is less emphasized. A gendersensitive approach to rehabilitation should recognize that women's economic needs are not inferior to men's. Hence, occupational rehabilitation is as valid and important for women as it is for men. Programs, for women as well as for men, which fail to provide a response to the need for victims of trafficking to earn an independent living are bound to fail. Rehabilitation should, as much as possible, include vocational programs, business development, loans to open businesses, and employment networking between victims and public and private organizations (Rosenberg, 2008). As our research demonstrates, working permits and unemployment allowances are crucial, and interlinked to the emotional, not just the economic, rehabilitation of victims.

The findings also show that women, more than men, are subjected to restrictive rules related to their freedom of movement. Likewise, in other countries, rehabilitation approaches that were common in the past, but are no longer acceptable, imposed significant restrictions on the autonomy and freedom of movement of trafficking survivors during their stay in shelters. (At the time, most of the residents of shelters were women trafficked for prostitution.) In some cases, women attempted to escape from the shelters, since they were held there against their wishes and perceived this experience as re-victimization (LevineFraiman in Hacker \& Cohen, 2012, chap. 2). This line of thought correlates with Lee (2014), who explores the gendered practices of protective custody for trafficking victims in Asia, and problematizes the intersections of gendered systems of power and discipline under a paternalistic state. Arguments for "rescuing" trafficked survivors are typically articulated in relation to women and girls who are perceived as "unruly", vulnerable to sexual exploitation, or in need of reform (Lee, 2014). The behavior of some of the survivors in the shelters-such as attempting to escape, or resisting therapy-can be understood using Scott's (1985) concept of "everyday resistance". Everyday resistance is a practice entangled with power and domination. Indeed, shelters can be considered, in Goffman's terms (1961), as "total institutions" (DeWard \& Moe, 2010). Providing emotional rehabilitation is an inherent challenge in a total institution. A feminist approach will encourage enhancing the freedom of trafficking survivors to choose their everyday routine and to gain control over their lives post-trafficking.

It is important to further emphasize that gender sensitive therapy is highly relevant for men and not only for women. For example, the Gender Role Conflict (GRC) theory is applicable when using gender sensitive therapy with men. O'Neil, Good \& Holmes (1995) define GRC as "a psychological state in which socialized gender roles have negative consequences for the person or others. Gender role conflict occurs when rigid, sexist, or restrictive gender roles result in personal restriction, devaluation, or violation of others or self". Therapy itself is often incongruent with masculine stereotypes. In order to help therapists make assessments of men and to improve clinical interventions, GRC researchers offer a diagnostic schema with seven GRC assessment domains, including: (a) The therapist's selfassessment; (b) Diversity and oppression related to race, class, age, religion, ethnicity, sexual orientation etc.; (c) Men's defenses; (d) Men's emotionality and restrictive emotionality; (e) Men's distorted cognitive schemas about masculinity ideology; (f) Men's patterns of GRC and gender role devaluations, restrictions, and violations; and (g) Men's need for information, psychoeducation, and preventive programs (O'Neil, 2008).

Moreover, as mentioned above, men usually tend not to participate in emotional therapy, even in times of hardship or in the wake of traumatic events (McCarthy \& Holliday, 2004). Seeking emotional help conflicts with masculine expectations, which demand that men are strong, tough and independent (Yousaf et al., 2014). These stereotypes are constituted by feelings like shame in admitting they need help (Krugman, 1995). In many cases, there is a contradiction between a therapist's expectations for emotional openness and the masculine socialization which encourages the suppression of one's emotions (Cochran, 2005). Such gender norms may ultimately render men vulnerable to developing severe emotional distress (Cochran \& Rabinowitz, 2003; Lisak, 2000). Therefore, close attention should be paid to the male residents of shelters and rehabilitation centers like Atlas, and to their need for emotional assistance. Turning a blind eye to their emotional needs replicates the gender norms which class men as "tough", equipped to deal with emotional turmoil by themselves. The fact that there are hardly any rehabilitation centers in other countries for the male victims of trafficking and slavery (Levine-Fraiman in Hacker \& Cohen, 2012, chap. 2), is also worth mentioning, since it is a strong indication that the emotional needs of these victims are not addressed worldwide.

Gender is a major aspect of identity and is the focus of this article; however, feminist theories on intersectionality (Dill, McLaughlin, \& Nieves, 2007), remind us that rehabilitation services must take into account other aspects of identity and identity intersections, and must be sensitive to the different ethnicities, languages and cultures of the victims. As the examples of 
Ma'agan and Atlas demonstrate, the legal terms "trafficking victims" and "slavery victims" relate to a heterogeneous population, which call for highly sensitive and adaptive therapeutic interventions. Culturallysensitive rehabilitative work requires considerable knowledge, particularly in sensitive interpersonal areas such as the perception of authority, ways of requesting and receiving help, perception of time, and emotional restrictions (Caldwell \& White, 2000; Liu, 2005; Sue, 2000). For example, symptoms of emotional distress may manifest themselves in different ways, influenced by cultural background (Jenkins, 1996; Schubert \& Punamäki, 2011). In addition, as Liu (2005) reviewed, the desire to seek emotional help could be hindered by the fear that the counselor may not understand the norms and values of the client, or a lack of knowledge concerning the mechanisms of therapy.

For those who are reluctant to receive therapeutic interventions, it is possible to implement other kinds of intervention such as psycho-education, in order to legitimate their experiences and provide necessary knowledge (Schaub \& Williams, 2007). The literature exemplifies pathways of rehabilitation interventions that are sensitive to the intersection of gender and culture. Still, there is no coherent, multicultural approach to therapy with men which incorporates their diversity (O'Neil, 2008). A pathway for therapy sensitive to gender and culture includes less traditional and non-verbal therapeutic techniques such as using music and art, which are specifically recommended with regard to rehabilitation in African cultural settings (Caldwell \& White, 2000).

Likewise, in light of men's possible difficulties in expressing emotions, and the encouragement in some non-Western cultures towards emotional repression, Cognitive Behavior Therapy (CBT) might offer a more accessible therapeutic option than traditional dynamic therapy (Mahalik, 2000). CBT focuses on changing the patterns of thinking and behavior that affect one's emotional state, and has been proven to be effective with asylum seekers and refugees (Grey \& Young, 2008; Schulz, Resick, Huber, \& Griffin, 2006), including victims of trafficking and slavery.

Another therapeutic model, which takes into account culture and gender, emphasizes three important dimensions: (a) Beliefs and attitudes (how counselors think and feel about clients outside the majority group, while also stressing the importance of recognizing how those beliefs might interfere with the therapeutic process); (b) Knowledge (referring to specific information about working with individuals outside the majority group who, in this case, experience gender-role-related issues); and (c) Skills (dealing with specific techniques aimed at serving people from minority cultures) (Liu, 2005; Sue, Arredondo, \& McDavis, 1992).

A major question arises concerning the scope and nature of the emotional and vocational rehabilitation that the shelters for human trafficking could-or should-provide. For instance, the Israeli government's aim in establishing Ma'agan and Atlas was to provide short-term rehabilitation of up to one year in the shelters. A common characteristic of survivors of trafficking is that they suffer high rates of emotional distress and psychiatric symptoms (Stenmark, Guzey, Elbert, \& Holen, 2014). Effective mental therapy may take years. In addition, processing the emotional implications of traumatic experiences requires stability and good timing (Herman, 1997). In practice, usually, the lives of the residents of rehabilitation centers and shelters for human trafficking are unstable and their legal status is uncertain, as most of them are not citizens of the country to which they were trafficked (Halili, in Hacker \& Cohen, 2012, chap. 3.8). When defining the aim and the nature of emotional and vocational rehabilitation that should be provided by shelters, we must keep in mind the fact that the shelters are one step in the residents' rehabilitation process, and that shelters are not usually intended to supply the full recovery and integration process. Hence, long-term rehabilitation programs in the hosting country and country of origin must be developed and sustained beyond residential periods in sheltered.

Moreover, as experience is developed in the provision of rehabilitation services for the victims of trafficking and as intervention by international agencies increases, different approaches have emerged around the world regarding the best rehabilitation practices, with a critical perspective on the frameworks of shelters. These approaches prefer rehabilitation based on integration in the community, as opposed to secluded shelters. They also advocate cooperation between governmental and non-governmental bodies, and seek to strike a balance between psychological tools and social empowerment. These approaches emphasize human rights rather than charity (Locke, 2010). Finally, we found very little material-whether academic or activist in nature-proposing detailed criteria for evaluating the success of emotional rehabilitation with victims of trafficking (see, also, Lee, 2014).

While much more study and theorization is required in order to form a fully developed gendersensitive rehabilitation theory for the victims of trafficking and slavery, the findings of our study, together with the theoretical insights and practical guidelines developed by feminist thinkers and practitioners, highlight the main vectors that should underline such a theory: Each survivor should enjoy a specially tailored rehabilitation plan, which takes into consideration the nature of abuse suffered and based on the presumption that each survivor is a specialist of his or her own life and needs, strengths and weaknesses. Gendersensitive rehabilitation for victims of traffickingwhether in shelters or other frameworks-needs to take into account power relations, be aware of contex- 
tual and professional gender biases, honor the human rights of victims including the freedom of movement, and provide emotional assistance for both women and men, and in ways that acknowledge and negotiate appropriately the gendered paths of asking for help and resisting it. The rehabilitation process should also secure vocational stability and income and adjusted development of everyday skills for both men and women, address the parenthood of the survivors with children, and safely integrate the survivors back into an accepting community in order to prevent re-trafficking. Lastly, gender-sensitive rehabilitation process in shelters, if adopted, should be perceived as only one component of the much broader and challenging endeavor of addressing both the social causes that enable trafficking and its outcomes.

\section{Acknowledgements}

We dedicate this article to the memory of our beloved colleague Prof. Orna Cohen, of the Bob Shapell School of Social Work at Tel Aviv University. Prof Cohen conducted, with the first author and with the assistance of the second and third authors, the study on the Israeli shelters for survivors of human trafficking, which yielded the findings that support this article. The research on the shelters was supported by the Joint Distribution Committee-Israel. We are grateful to the Hotline for Refugees and Migrants for initiating the study of the shelters, and to the Israel Ministry of Welfare and the Keshet association for making the shelters accessible for research. We would also like to thank the interviewed victims of human trafficking and immigrationrelated abuse, officials, professionals and activists in the research field, for their willingness to share their knowledge, experience and impressions. We thank the Paula Goldberg Fund for the publication grant. Responsibility for the interpretations and opinions in this article is that of the authors alone.

\section{Conflict of Interests}

The authors declare no conflict of interests.

\section{References}

Adams, C. (2011). Re-trafficked victims: How a human rights approach can stop the cycle of revictimization of sex trafficking victims. The George Washington International Law Review, 43, 201-234.

Armstrong, H. C. (2008). Rebuilding lives: An introduction to promising practices in the rehabilitation of freed slaves. Washington, DC: Free the slaves. Retrieved from https://freetheslaves.net/Document. Doc?id=60

Aronowitz, A. A. (2009). Human trafficking, human misery: The global trade in human beings. West- port: Praeger.

Bales, K., \& Soodalter, R. (2009). The slave next door: Human trafficking and slavery in America today. Berkeley: University of California Press.

Bhushan, B., \& Hussain, D. (2007). Posttraumatic growth: Theory, research, and issues. Psychological Studies, 52(1), 45-53.

Bjerkan, L. (2005). A life of one's own: Rehabilitation of victims of trafficking for sexual exploitation. Oslo: Fafo.

Blanchet, T. (2002). Beyond boundaries: A critical look at women labour migration and the trafficking within. Dhaka: USAID.

Bosworth, M., Hoyle, C., \& Dempsey, M. M. (2011). Researching trafficked women on institutional resistance and the limits to feminist reflexivity. Qualitative Inquiry, 17(9), 769-779.

Bronfenbrenner, U. (1979). The ecology of human development: Experiments by nature and design. Cambridge, MA: Harvard University Press.

Brunovskis, A., \& Surtees, R. (2007). Leaving the past behind: When victims of trafficking decline assistance. Oslo: Fafo.

Caldwell, L. D., \& White, J. L. (2000). African-centered therapeutic and counseling interventions for African American males. In J. R. Brooks \& G. E. God (Eds.), The new handbook of psychotherapy and counseling with men: A comprehensive guide to settings, problems, and treatment approaches (pp. 737-753). San Francisco: Jossey-Bass.

Carter, T. A. (2012). Resiliency in survivors of human trafficking: fan exploratory study of clinicians' perspectives of protective factors. Unpublished dissertation, Smith College, Massachusetts, USA.

Cavaglion, G. (2010). Trafficking in women for sex in a glocal context: The case of Israel, In M. Shechory, S. Ben-David, \& D. Soen (Eds.), Who pays the price? Foreign workers, society, crime and the law (pp. 201-212). New York: Nova Science.

Chantler, K. (2005). From disconnection to connection: "Race", gender and the politics of therapy. British Journal of Guidance \& Counselling, 33(2), 239-256.

Cochran, S. V. (2005). Evidence-based assessment with men. Journal of clinical psychology, 61(6), 649-660.

Cochran, S. V., \& Rabinowitz, F. E. (2003). Gendersensitive recommendations for assessment and treatment of depression in men. Professional Psychology: Research and Practice, 34(2), 132-140.

Cwikel, J., \& Hoban, E. (2005). Contentious issues in research on trafficked women working in the sex industry: Study design, ethics, and methodology. Journal of Sex Research, 42(4), 306-316.

Davidovich, R. (2009). Din veheshbon peilut sherutey hatipul bekorbanot sahar bivney adam [Report on the services provided for human trafficking victim]. Retrieved from http://atlas-shelter.org.il/AllSites/ 857/Assets/darush\%20oved\%202009.pdf 
Deering, C. G., \& Gannon, E. J. (2005). Gender and psychotherapy with traditional men. American journal of psychotherapy, 59(4), 351-360.

De Leon, G. (2000). The therapeutic community: Theo$r y$, model, and method. New York: Springer.

DeWard, S. L., \& Moe, A. M. (2010). Like a prison: Homeless women's narratives of surviving shelter. Journal of Sociology and social welfare, $37(1)$, 115-135.

Dill, B. T., McLaughlin, A. E., \& Nieves, A. D. (2007). Future directions of feminist research: Intersectionality. In: S. N. Hesse-Biber (Ed.), Handbook of Feminist Research (pp. 629-637). Thousand Oaks: Sage.

Dominelli, L., \& Campling, J. (2002). Feminist social work theory and practice. Basingstoke: Palgrave.

Ezioni, L. (2013). Hashinuy hamishpati be-averat hasahar benashim be-Israel: Ha'atid hama'asi over derech hateoria [The legal change in the trafficking in women offence in Israel: The practical future goes through the theory]. ShaareY Mishpat, 6, 161220.

Gallagher, A. T., \& Chuang, J. (2012). The use of indicators to measure government responses to human trafficking. In S. E. Merry, A. Fisher, \& K. Davis (Eds.), Governance by indicators: Global power through quantification and ranking (pp. 317-343). Oxford: Oxford University Press.

Gilbert, L. A., \& Scher, M. (2009). Gender and sex in counseling and psychotherapy. Eugene: Wipf and Stock Publishers.

Goffman, E. (1961). The characteristics of total institutions. In N. Etzioni (Ed.), A sociological reader on complex (pp. 312-338). New York: Holt, Rinehart \& Winston.

Goltsman, V. (2010). Masach shahor: Sicum peilut sherutey hatipul bekorbanot sahar bivney adam [Black screen: Summary of activities of the sheltering services for victims of trafficking]. Retrieved from http://atlas-shelter.org.il/AllSites/857/Assets/ masah shahor 2010.pdf

Good, G. E., Gilbert, L. A., \& Scher, M. (1990). Gender aware therapy: A synthesis of feminist therapy and knowledge about gender. Journal of Counseling \& Development, 68(4), 376-380.

Good, G. E., Thomson, D. A., \& Brathwaite, A. D. (2005). Men and therapy: Critical concepts, theoretical frameworks, and research recommendations. Journal of Clinical Psychology, 61(6), 699-711.

Grey, N., \& Young, K. (2008). Cognitive behaviour therapy with refugees and asylum seekers experiencing traumatic stress symptoms. Behavioural and Cognitive Psychotherapy, 36(1), 3-19.

Hacker, D. (2015). Strategic compliance in the shadow of transnational anti-trafficking law. Harvard $\mathrm{Hu}$ man Rights Journal, 28, forthcoming.

Hacker, D., \& Cohen, O. (2012). Research report: The shelters in Israel for survivors of human trafficking (submitted to the US Department of State). Retrieved from http://www2.tau.ac.il/InternetFiles/ news/UserFiles/The\%20Shelters\%20in\%20lsrael.pdf

Haikin, R., \& Safran, H. (2011). Immigration, women and prostitution: The case of women from the former Soviet Union in Israel. In R. L. Dalla, L. M. Baker, J. DeFrain, \& C. Williamson (Eds.), Global perspectives on prostitution and sex trafficking: Africa, Asia, Middle East, and Oceania (pp. 223-244). Lanham: Lexington Books.

Halley, J. (2013). Daphna Hacker and Orna Cohen. "The shelters in Israel for survivors of human trafficking". US Department of State (2012). Retrieved from http://traffickingroundtable.org/2013/04/daphnahacker-and-orna-cohen-the-shelters-in-israel-forsurvivors-of-human-trafficking-us-department-ofstate-2012

Herman, J. L. (1997). Trauma and recovery. New York: Basic books.

Hotline for Migrant Workers. (2011). "The dead of the wilderness": Testimonies from Sinai Desert, 2010. Retrieved from http://ardc-israel.org/sites/default/ files/testimonies_from_sinay_122010.pdf

Immigration Authority. (2013). Netoney zarin be'Israel [Data on aliens in Israel]. Retrieved from http:// www.piba.gov.il/PublicationAndTender/ForeignWo rkersStat/Documents/foreign_stat_032013.pdf

Israeli Government. (2002). Hakamat miklat lekorbanot sahar bivney adam le-isuk biznut [Establishment of a shelter for the victims of human trafficking for the purpose of prostitution] (Decision No. 2806 of the 29th Government). Retrieved from http://index. justice.gov.il/Units/Trafficking/IsraelFight/Activity/ Pages/governmentresolutions.aspx

Israeli Government. (2007). Tochniot leumiot lama' avak basahar bivney adam [National plans to combat human trafficking] (Decision No. 2670 of the 31th government). Retrieved from http://index. justice.gov.il/Units/Trafficking/IsraelFight/Activity/ Pages/governmentresolutions.aspx

Jenkins, J. H. (1996). Culture, emotion, and PTSD. In A. J. Marsella, M. J. Friedman, \& E. H. Spain (Eds.), Ethnocultural aspects of posttraumatic stress disorder: Issues, research, and clinical applications (pp.165-182). Washington, DC: American Psychological Association.

Krugman, S. (1995). Male development and the transformation of shame. In R. F. Levant \& W. S. Pollack (Eds.), A new psychology of men (pp. 91-126). NY: Basic Books.

Lee, M. (2014). Gendered discipline and protective custody of trafficking victims in Asia. Punishment \& Society, 16(2), 206-222.

Levenkron, N., \& Dahan, D. (2004). Sahar Benashim BeIsrael Behasut Shilton Hahok [Trafficking in Women in Israel under the protection of the law]. Theory \& Citric, 24, 9-44. 
Lisak, D. (2000). Male survivors of trauma. In J. R. Brooks \& G. E. God (Eds.), The new handbook of psychotherapy and counseling with men: A comprehensive guide to settings, problems, and treatment approaches (pp. 263-277). San Francisco: Jossey-Bass.

Liu, W. M. (2005). The study of men and masculinity as an important multicultural competency consideration. Journal of Clinical Psychology, 61(6), 685-697.

Locke, R. A. (2010). Rescued, rehabilitated, returned: Institutional approaches to the rehabilitation of survivors of sex trafficking in India and Nepal (Unpublished doctoral dissertation). University of Denver, Colorado, USA.

Mahalik, J. R. (2000). Cognitive therapy for men. In J. R. Brooks \& G. E. God (Eds.), The new handbook of psychotherapy and counseling with men: A comprehensive guide to settings, problems, and treatment approaches (pp. 544-564). San Francisco: JosseyBass.

McCarthy, J., \& Holliday, E. L. (2004). Help-seeking and counseling within a traditional male gender role: An examination from a multicultural perspective. Journal of Counseling \& Development, 82(1), 25-30.

Mejía, X. E. (2005). Gender matters: Working with adult male survivors of trauma. Journal of Counseling \& Development, 83(1), 29-40.

Ministry of Welfare. (2008). Mechraz le-hafa'lat misgarot lekorbanot sahar liznut, le-avdut u-le-avodot kfiya [Tender for the operation of frameworks for victims of trafficking for prostitution, slavery and forced labor] (Public Tender 199/2008). Israel: Ministry of Social Services.

Nathan, G. (2009). Ovdim zarim be-Israel [Migrant workers in Israel]. Retrieved from http://www. knesset.gov.il/mmm/data/pdf/m02210.pdf

O'Neil, J. M. (2008). Summarizing 25 years of research on men's gender role conflict using the gender role conflict scale new research paradigms and clinical implications. The Counseling Psychologist, 36(3), 358-445.

O’Neil, J. M., Good, G. E., \& Holmes, S. (1995). Fifteen years of theory and research on men's gender role conflict: New paradigms for empirical research. In R. F. Levant \& W. S. Pollack (Eds.), A new psychology of men (pp. 164-206). NY: Basic Books.

Rosenberg, R. (2008). Best practices for programming to protect and assist victims of trafficking in Europe and Eurasia: Final report. Retrieved from www.lastradainternational.org/lsidocs/Best_Practic es_for_Programming_to_Protect_and_Assist_Victi ms_of_Trafficking_in_Europe_and_Eurasia.pdf

Rosso, B. D., Dekas, K. H., \& Wrzesniewski, A. (2010). On the meaning of work: A theoretical integration and review. Research in organizational behavior, 30, 91-127.

Schaub, M., \& Williams, C. (2007). Examining the relations between masculine gender role conflict and men's expectations about counseling. Psychology of Men \& Masculinity, 8(1), 40-52.

Schubert, C. C., \& Punamaki, R. L. (2011). Mental health among torture survivors: Cultural background, refugee status and gender. Nordic journal of psychiatry, 65(3), 175-182.

Schulz, P. M., Resick, P. A., Huber, L. C., \& Griffin, M. G. (2006). The effectiveness of cognitive processing therapy for PTSD with refugees in a community setting. Cognitive and Behavioral Practice, 13(4), 322 331.

Scott, J. C. (1985). Weapons of the weak: Everyday forms of peasant resistance. New Haven, CT: Yale University Press.

Shigekane, R. (2007). Rehabilitation and community integration of trafficking survivors in the United States. Human Rights Quarterly, 29(1), 112-136.

Stenmark, H., Guzey, I. C., Elbert, T., \& Holen, A. (2014). Gender and offender status predicting treatment success in refugees and asylum seekers with PTSD. European Journal of Psychotraumatology, 5(20803), 1-7. doi:10.3402/ejpt.v5.20803

Sue, D. W. (2000). Asian American masculinity and therapy: The concept of masculinity in Asian American males. In J. R. Brooks \& G. E. God (Eds.), The new handbook of psychotherapy and counseling with men: A comprehensive guide to settings, problems, and treatment approaches (pp. 780-795). San Francisco: Jossey-Bass.

Sue, D. W., Arredondo, P., \& McDavis, R. J. (1992). Multicultural counseling competencies and standards: A call to the profession. Journal of Counseling \& Development, 70(4), 477-486.

Turner, J., \& Kelly, L. (2008). Nordic Baltic pilot project for the support, protection, safe return and rehabilitation of women victims of trafficking for sexual exploitation: evaluation report. London: London Metropolitan University.

Twigg, N. M. (2012). A description of services provided by US rehabilitation centers for domestic sex trafficking survivors (Doctoral dissertation). University of St. Francis, Illinois, U.S.A.

United Nations. (2000). Protocol to prevent, suppress and punish trafficking in persons especially women and children, supplementing the United Nations Convention against Transnational Organized Crime (opened for signature Dec. 12, 2000, S. TREATY DOC. NO. 108-16, 2237 U.N.T.S. 319, entered into force Dec. 25, 2003). New York: United Nations.

United States Agency for International Development. (2007). The rehabilitation of victims of trafficking in group residential facilities in foreign countries. Washington, DC: Office of Women in Development, USAID. Retrieved from http://pdf.usaid.gov/pdf_ docs/PNADK471.pdf

US State Department. (2014). Trafficking in persons report. Retrieved from http://www.state.gov/j/tip/ 
rls/tiprpt/2014/index.htm

Williams, J. (1999). Unbending gender: Why family and work conflict and what to do about it. Oxford: Oxford University Press.
Yousaf, O., Popat, A., \& Hunter, M. S. (2014). An investigation of masculinity attitudes, gender, and attitudes toward psychological help-seeking. Psychology of Men \& Masculinity. doi:10.1037/a0036241

\section{About the Authors}

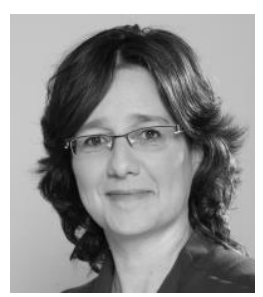

\section{Dr. Daphna Hacker}

Daphna Hacker is a Senior Lecturer at the Tel Aviv University Law Faculty and Women and Gender Studies Program. Her empirical and normative work focuses on the intersection of law, family and gender. Her books and numerous articles published in leading legal and socio-legal journals deal with issues such as child custody, inheritance, and globalized families.

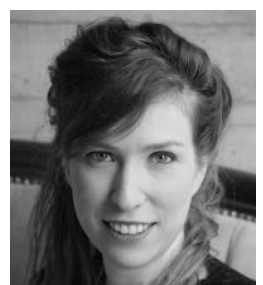

\section{Yaara Levine-Fraiman}

Yaara Levine-Fraiman is a psychologist at the Educational Psychological Services, Tel-Aviv-Yafo Municipality. She provides consultation, guidance and psychological assessment for children and adolescents from diverse populations including asylum seekers and labor immigrants. Her MA in social psychology from Tel Aviv University focused on gender, parenting, adolescence and qualitative research.

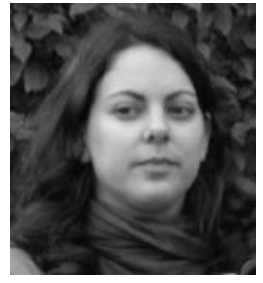

\section{Idan Halili}

Idan Halili is a student of law (LL.B) and social work (BSW) in the Hebrew University of Jerusalem. She had worked with victims of trafficking at the Hotline for Migrant Workers (today called The Hotline for Refugees and Migrants) in 2006-2008. 